\title{
The Effectiveness of Different Doses of Intravenous Immunoglobulin on Severe Hand, Foot and Mouth Disease: A Meta-Analysis
}

\author{
Wei Jiao ${ }^{a} \quad$ Si-Ran Tan ${ }^{a} \quad$ Yan-Feng Huang ${ }^{b} \quad$ Li-Hong Mu ${ }^{a} \quad$ Yang Yang $^{b}$ \\ Yan Wang ${ }^{c}$ Xue-E Wu ${ }^{a}$ \\ ${ }^{a}$ Department of Epidemiology, School of Public Health and Management, Chongqing, PR China; ${ }^{b}$ Division of \\ Infectious Disease and Gastroenterology, Children's Hospital of Chongqing Medical University, Chongqing, \\ PR China; ' Department of Foreign Languages, Chongqing Medical University, Chongqing, PR China
}

\section{Significance of the Study}

- The use of intravenous immunoglobulin (IVIG) in hand, food and mouth disease (HFMD) is contentious. We present a meta-analysis in which we found that IVIG improves HFMD, with a high-dose having better prognosis. Thus, high-dose IVIG can be used in severe HMFD, while low-dose IVIG can be used in stable patients.

\section{Keywords}

Intravenous immunoglobulin · Hand, foot and mouth disease

\section{Abstract \\ Objective: To conduct a meta-analysis of evidence from ran- domized controlled trails (RCTs) of different doses of intrave- nous immunoglobulin (IVIG) in children with severe hand, foot and mouth disease (HFMD) to provide the scientific ba- sis for clinical practice. Methods: A search of PubMed-Med- line, CNKI, Wanfang, and VIP database (until June 30, 2017) was performed and Software RevMan5.3 was used to evalu- ate the effect of different doses of IVIG on HFMD in RCTs. We used random-effects models (or fixed-effects models) and generic inverse variance methods to process quantitative data, followed by a leave-one-out method for sensitivity analysis. Results: From a total of 420 entries identified via searches, 8 RCTs involving 1,450 patients were included in}

\begin{tabular}{ll}
\hline KARGER & $\begin{array}{l}\text { (c) } 2019 \text { The Author(s) } \\
\text { Published by S. Karger AG, Basel }\end{array}$ \\
E-Mail karger@karger.com & $\begin{array}{l}\text { This is an Open Access article licensed under the Creative Commons } \\
\text { Attribution-NonCommercial-4.0 International License (CC BY-NC) } \\
\text { (http://www.karger.com/Services/OpenAccessLicense), applicable to } \\
\text { the online version of the article only. Usage and distribution for } \\
\text { commercial purposes requires written permission. }\end{array}$
\end{tabular}

the final analysis. The results of the meta-analysis showed that compared with conventional therapy alone, conventional therapy combined with IVIG had shorter fever clearance time, shorter rash regression time, and shorter clinical cure time. Subgroup analyses showed that the high-dose group (1 $\mathrm{g} / \mathrm{kg} /$ day) had shorter fever clearance time ( $p<$ $0.05)$, shorter rash regression $(p<0.05)$, shorter remission time of neurological symptoms $(p<0.05)$, but longer clinical cure time $(p>0.05)$. Conclusion: The high-dose group has a better prognosis; however, the advantages and disadvantages should be carefully considered when deciding the doses in the treatment of severe HFMD.

\section{2019 The Author(s)}

Published by S. Karger AG, Basel

Wei Jiao and Si-Ran Tan are co-first authors, and contributed equally to the article.

\section{Li-Hong $\mathrm{Mu}$}

Department of Epidemiology, School of Public Health and Management Chongqing Medical University, Yi Xue Yuang Road No. 1

Chongqing 400016 (PR China)

E-Mail1097123703@qq.com 


\section{Introduction}

Hand, foot and mouth disease (HFMD) is an acute infectious disease caused by infection with serotypes of Enterovirus A, most commonly by enterovirus A71 and coxsackievirus A16. It usually occurs in preschool children, especially those under 3 years of age. It can spread through the digestive tract, respiratory tract, and close contact; the main source of infection is patients and individuals with suppressive infection. The clinical manifestations are a maculopapular or vesicular rash (mainly present in hands, foot, mouth and other parts), and some children may have complication such as respiratory infections and viral myocarditis $[1,2]$. The disease progresses rapidly in a small number of patients [3], with high mortality and disability rates [4].

Clinical data have shown that intravenous immunoglobulin (IVIG) has a protective or mitigating effect on some viral and bacterial infections [5-9], but there is no high-level evidence for its use in severe HFMD.

Nevertheless, the use of IVIG has been adopted and recommended by several national and international guideline committees, including the WHO [10], and is now part of standard of care for complicated HFMD in several countries and included in national insurance programs. However, the benefits and severe adverse events have not been studied systematically [11]. We included in the 5 metaanalyses literature on the use of IVIG for the treatment of severe HFMD before June 30, 2017, aiming to provide theoretical and decision-making references for clinical treatment. This analysis followed the PRISMA guidelines.

\section{Material and Methods}

\section{Search Strategy and Study Selection}

Two authors independently searched PubMed-Medline, CNKI (China National Knowledge Infrastructure), The Cochrane Library, Wanfang database, and VIP database (until June 30, 2017) in Chinese and English with different combinations of "Intravenous Immunoglobulin," "IVIG," and "Hand, Foot and Mouth Disease" to identify prospective studies evaluating the effect of different doses of IVIG in children with severe HFMD. Documents were filtered according to the inclusion and exclusion criteria. First, by reading the title and abstract, we excluded duplicate publications and publications that did not meet the standard. Then, by reading the full text and details such as interventions, outcome measures, complete baseline data, we decided which publications would be included. We excluded narrative editorials, letters, reviews, opinion pieces, papers, comments, or any publications lacking primary data.

Specific diagnostic criteria of severe HFMD according to the Guideline for the Diagnosis and Treatment of Hand, Foot and Mouth Disease Guide (2010 edition) [12] and Expert Consensus on Clinical Treatment of Enterovirus 71 (EV71) Infection in Severe Cases (2011 edition) [13], referred to here as Guide (2010 edition) and Expert Consensus (2011 edition), are as follows (definite when meeting one): (1) Enterovirus (CoxA16, EV71, etc.)-specific nucleic acid detection positive; (2) intestinal virus in the division and identified as CoxA16, EV71 or other enterovirus that can cause HFMD; and (3) acute and convalescent serum CoxA16, EV71 or other intestinal virus-neutralizing antibodies that cause HFMD are more than 4 times higher.

The IVIG group received both conventional treatment and IVIG (IVIG for 2-3 days), while the control group only received conventional treatment. IVIG treatment consisted of a high-dose group (1.0 $\mathrm{g} / \mathrm{kg} /$ day), a medium-dose group (0.4-0.5 g/kg/day), and a low-dose group $(0.2 \mathrm{~g} / \mathrm{kg} /$ day). According to the Guide (2010 edition) and Expert Consensus (2011 edition), conventional treatment included isolation to avoid cross-infection keeping a balanced diet to maintain nutritional needs, caring for personal hygiene, especially for the skin and mouth, as well as having a good rest, giving some symptomatic treatments according to the state of illness, such as mannitol for dehydration, fever reduction, antiviral treatment, reduction of intracranial pressure, small doses of glucocorticoid, keeping the respiratory tract unobstructed as well as some supportive treatments, such as supplementation with vitamin C.

The inclusion criteria were as follows: (a) research type: randomized controlled trials (RCTs) type; (b) research subjects: children with severe HFMD; (c) research purposes: to evaluate the effect of different doses of IVIG in children with severe HFMD and the intervention arms are as above; and (d) accessible information: extractable basic data and literature information, and clear clinical data.

Exclusion criteria were: (a) non-RCTs; (b) the doses of conventional treatment did not match the inclusion criteria; (c) the grade of HFMD was not clear (our research aimed at severe HFMD); (d) the relevant information could not be extracted or clinical data was not clear; (e) basic data could not be extracted from the literature; and (f) duplicate publication.

\section{Data Extraction}

The full text of studies meeting the inclusion criteria was selected and screened to determine whether it was eligible. Extracted data included: (a) basic information: author, publishing time, number of cases, research subjects, age distribution; (b) interventions: drug name, dosage, duration of treatment; and (c) effect indicators: total effective rate, fever reduction time, rash regression time, remission time of neurologic symptoms, clinical cure time (normal body temperature with disappearance of disease symptoms and signs), length of hospital stay, and adverse reaction rate.

\section{Quality Assessment}

The quality of the included studies was assessed by two authors using the Cochrane Collaboration tool: (a) adequacy of random distribution method; (b) allocation concealment; (c) blind method; (d) patients and outcomes; (e) data integrity (f) selective outcome reporting; and $(\mathrm{g})$ other potential bias.

\section{Data Analysis}

Meta-analysis was performed with the use of RevMan5.3 software. Mean differences were used as indicators for measurement data and relative risk values as indicators for count data, which provide point estimates and 95\% CI (standard of test $\mathrm{a}=0.05$ ) for each effect. (a) Heterogeneity evaluation of the literatures: at first, the 
Table 1. General characteristics and quality assessment of the studies included in the meta-analysis

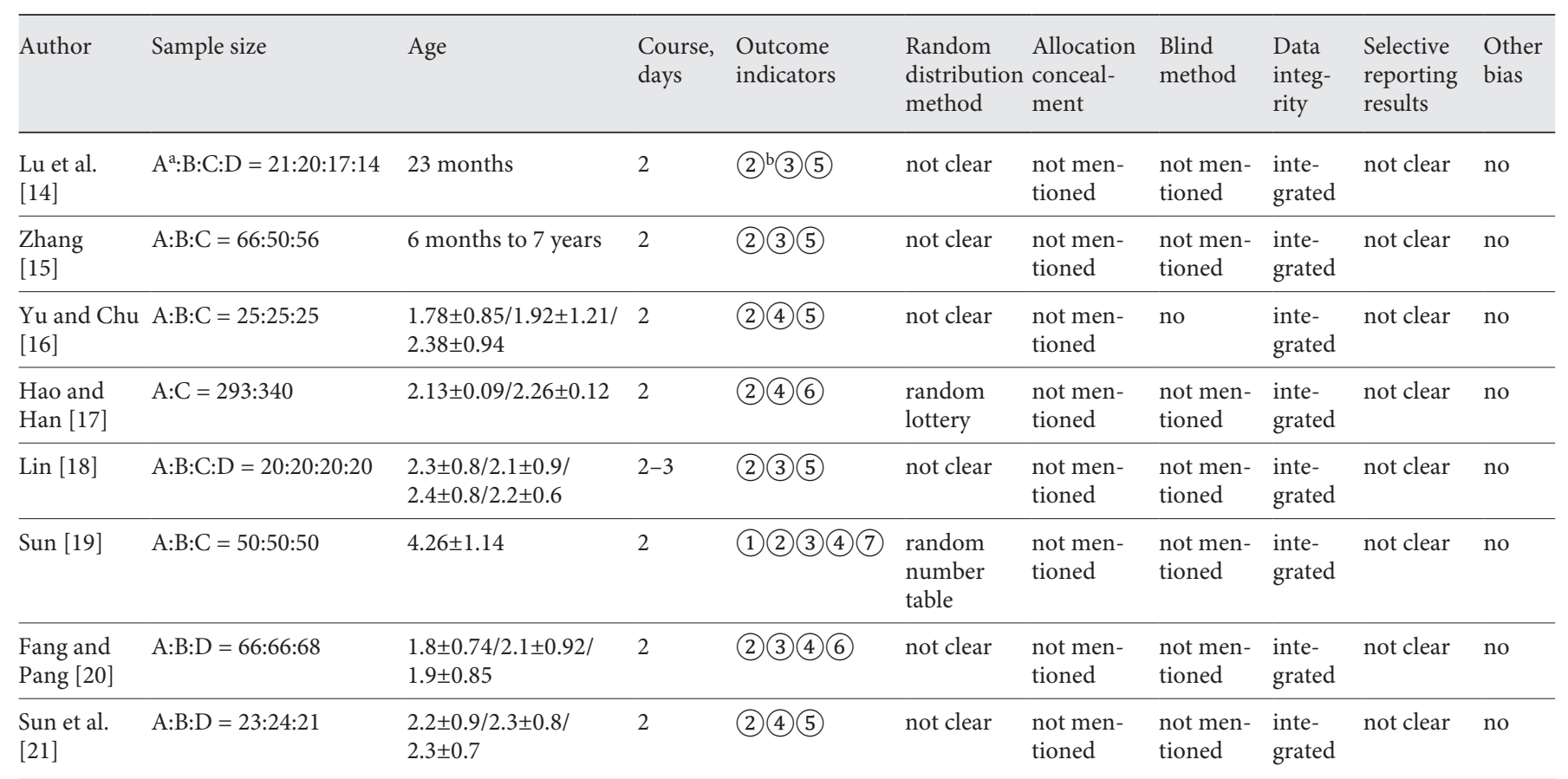

a A: IVIG 1 g/kg/day; B: IVIG 0.4-0.5 g/kg/day; C: IVIG 0.2 g/kg/day) D: control group: conventional therapy. ${ }^{\mathrm{b}}$ (1) Total effective rate; (2) fever clearance time; (3) rash regression time; (4) remission time of neurological symptoms; (5) clinical cure time (normal body temperature with disease symptoms and signs disappearing); (6) length of hospital stay; (7) adverse reaction rate.

heterogeneity between results was calculated with the use of the $\chi^{2}$ test, then the heterogeneity was quantitatively assessed with the use of the $I^{2}$ index, and when the $I^{2}$ value was $>50 \%$, it was considered that there was statistical heterogeneity between groups. If there was no statistical heterogeneity, then a fixed-effects model was used for meta-analysis. If there was statistical heterogeneity, then a subgroup analysis was conducted; if there was no statistical heterogeneity in subgroup analysis, a fixed-effects model was used, and if there was still statistical heterogeneity in subgroup analysis, a random-effects model was used or only descriptive analysis was conducted. Effect sizes were expressed as the weighted mean difference and 95\% CI. (b) Analysis of pooled effect sizes: $z$ test was used, and $p>0.05$ was considered as having no statistical difference, while $p<0.05$ was considered as having statistical differences. (c) Sensitivity analysis: the sensitivity analysis was conducted after exclusion of a few articles of poor quality; if the result of meta-analysis was stable, then this metaanalysis was valid. (d) Analysis of publication bias: funnel plots were drawn for the analysis of publication bias.

\section{Results}

\section{Results of Searches and Study Selection Process}

We identified a total of 420 citations, of which 409 records were included after exclusion of the duplicates. After screening titles and abstracts, 41 articles were included for further evaluation and 368 were excluded due to one or more of the following: study object did not match, intervention did not match, non-RCT studies, clinical data was unclear and efficacy indicators did not match. Finally, 8 studies [14-21] involving 1,450 cases meeting all inclusion criteria for this meta-analysis were included.

\section{Characteristics and Quality Assessment of the Eligible Studies}

The 8 included studies were all RCTs and were all performed and reported according to CONSORT guidelines; they were not published in English language journals and were not indexed in PubMed. The characteristics and quality assessment of the included studies are summarized in Table 1 . These studies were published between 2010 and 2015. The mean age of participants ranged from 6 months to 7 years. The duration of the treatment among studies ranged from 2 to 3 days. The sample size of included literature ranged from 68 to 633 . There were only 2 articles describing the random distribution method [16, 19], which was not clarified in the other studies. Allocation concealment and whether the blind method was used was not made clear. 


\begin{tabular}{|c|c|c|c|c|c|c|c|c|c|c|c|c|}
\hline \multirow[t]{2}{*}{ Study or subgroup } & \multicolumn{3}{|c|}{ High-dose group } & \multicolumn{3}{|c|}{ Low-dose group } & \multirow{2}{*}{$\begin{array}{l}\text { Weight } \\
\%\end{array}$} & \multirow{2}{*}{$\begin{array}{l}\text { Mean difference } \\
\text { IV, fixed, } 95 \% \mathrm{Cl}\end{array}$} & \multirow{2}{*}{\multicolumn{2}{|c|}{$\begin{array}{l}\text { Mean difference } \\
\text { IV, fixed, } 95 \% \mathrm{Cl}\end{array}$}} & & \\
\hline & mean & SD & total & mean & SD & total & & & & & & \\
\hline \multicolumn{13}{|c|}{ Fever relieving time: IVIG $1 \mathrm{~g} / \mathrm{kg} /$ day versus IVIG $0.4-0.5 \mathrm{~g} / \mathrm{kg} /$ day } \\
\hline Fang and Pang [20], 2015 & 2 & 1.35 & 66 & 2.1 & 1.15 & 66 & 8.6 & $-0.10(-0.53,0.33)$ & & & - & \\
\hline Lin [18], 2015 & 4.7 & 1.3 & 20 & 4.8 & 1.6 & 20 & 1.9 & $-0.10(-1.00,0.80)$ & & & & \\
\hline Lu et al. [14], 2010 & 4.66 & 1.65 & 21 & 4.7 & 1.57 & 20 & 1.6 & $-0.04(-1.03,0.95)$ & & & & \\
\hline Sun [19], 2015 & 4.54 & 1.19 & 50 & 4.74 & 1.27 & 50 & 6.8 & $-0.20(-0.68,0.28)$ & & & - & \\
\hline Sun et al. [21], 2012 & 3.1 & 1.7 & 23 & 3.2 & 1.6 & 24 & 1.8 & $-0.10(-1.04,0.84)$ & & & & \\
\hline Yu and Chu [16], 2013 & 2.32 & 0.48 & 25 & 3.04 & 0.54 & 25 & 19.7 & $-0.72(-1.00,-0.44)$ & & $\rightarrow$ & & \\
\hline Zhang [15] , 2011 & 4.67 & 1.66 & 66 & 4.71 & 1.56 & 50 & 4.5 & $-0.04(-0.63,0.55)$ & & & & \\
\hline Subtotal $(95 \% \mathrm{Cl})$ & & & 271 & & & 255 & 45.0 & $-0.38(-0.57,-0.19)$ & & & & \\
\hline \multicolumn{13}{|c|}{ Heterogeneity: $\chi^{2}=10.16, \mathrm{df}=6(p=0.12) ; R^{2}=41 \%$} \\
\hline \multicolumn{13}{|c|}{ Test for overall effect: $z=3.96(p<0.0001)$} \\
\hline \multicolumn{13}{|c|}{ 2.1.2 Fever relieving time: IVIG $1 \mathrm{~g} / \mathrm{kg} /$ day versus IVIG $0.2 \mathrm{~g} / \mathrm{kg} /$ day } \\
\hline Hao and Han [17], 2010 & 3.6 & 1.71 & 293 & 3.81 & 1.63 & 340 & 23.1 & $-0.21(-0.47,0.05)$ & & $\rightarrow$ & & \\
\hline Lin [18], 2015 & 4.7 & 1.3 & 20 & 5.1 & 1.4 & 20 & 2.3 & $-0.40(-1.24,0.44)$ & & & & \\
\hline Lu et al. [14], 2010 & 4.66 & 1.65 & 21 & 5.21 & 1.61 & 17 & 1.5 & $-0.55(-1.59,0.49)$ & & & & \\
\hline Sun [19], 2015 & 4.54 & 1.19 & 50 & 5.26 & 1.65 & 50 & 5.0 & $-0.72(-1.28,-0.16)$ & & $\longrightarrow$ & & \\
\hline Yu and Chu [16], 2013 & 2.32 & 0.48 & 25 & 3.08 & 0.57 & 25 & 18.5 & $-0.76(-1.05,-0.47)$ & & $\rightarrow-$ & & \\
\hline Zhang [15], 2011 & 4.67 & 1.66 & 66 & 5.19 & 1.6 & 56 & 4.7 & $-0.52(-1.10,0.06)$ & & & & \\
\hline Subtotal $(95 \% \mathrm{Cl})$ & & & 475 & & & 508 & 55.0 & $-0.48(-0.65,-0.32)$ & & & & \\
\hline \multirow{2}{*}{\multicolumn{13}{|c|}{$\begin{array}{l}\text { Heterogeneity: } \chi^{2}=8.39, \mathrm{df}=5(p=0.14) ; R^{2}=40 \% \\
\text { Test for overall effect: } z=5.60(p<0.0001)\end{array}$}} \\
\hline & & & & & & & & & & & & \\
\hline Total $(95 \% \mathrm{Cl})$ & & & 746 & & & 763 & 100.0 & $-0.44(-0.56,-0.31)$ & & $\diamond$ & & \\
\hline \multicolumn{11}{|c|}{ Heterogeneity: $\chi^{2}=19.23, \mathrm{df}=12(p=0.08) ; R^{2}=38 \%$} & & \\
\hline \multirow{2}{*}{\multicolumn{9}{|c|}{$\begin{array}{l}\text { Test for overall effect: } z=6.81(p<0.0001) \\
\text { Test for subgroup differences: } \chi^{2}=0.68, \mathrm{df}=1(p=0.41) ; P^{2}=0 \%\end{array}$}} & -2 & -1 & 1 & 2 \\
\hline & & & & & & & & & & $\begin{array}{l}\text { h-dose } \\
\text { group }\end{array}$ & $\begin{array}{l}\text { Low-dose } \\
\text { group }\end{array}$ & \\
\hline
\end{tabular}

Fig. 1. Forest plot of subgroup analysis of fever clearance time among IVIG groups of different doses.

\section{Meta-Analysis}

Total Effective Rate

A meta-analysis [22] in the non-PubMed-indexed Chinese language literature on the efficacy of IVIG for the treatment of severe HFMD showed that the IVIG group had a higher total effective rate $(p<0.00001)$, shorter fever relieving time $(p<0.00001)$, shorter rash regression time $(p=0.0005)$, shorter remission time of nervous neurological symptoms $(p<0.00001)$, shorter mouth ulcer regression time $(p=0.004)$, and shorter average length of hospital stay $(p<0.00001)$ than conventional therapy alone.

In the current analysis, there were totally 564 patients in the high-dose group; 4 patients got worse and died (effective rate $99.6 \%$ ). There were 255 patients in the middle-dose group, and 7 got worse or died (effective rate $97.3 \%)$. In the low-dose group, 19 children got worse or died among 508 patients (effective rate $96.3 \%$ ). There was no significant difference between the high-dose group, middle-dose group, and low-dose group in terms of the total effective rate $(p<0.05)$.

Effectiveness of Different Doses of IVIG on Severe HFMD
Fever Clearance Time

There were a total of 8 studies involving 1,450 patients referring to fever clearance time [14-21]. The fixed-effects model was used for the data analysis, which showed that fever clearance time in IVIG groups of different doses was significantly shorter than that in the control group, and the difference was significant (mean difference $=-1.71 ; 95 \%$ CI -1.95 to $1.47 ; p<0.00001$; $\left.I^{2}=0 \%\right)$. Subgroup analysis was carried out among groups of different doses of IVIG, which showed that the fever clearance time in the high-dose group was significantly shorter than that in the low-dose group (mean difference $=-0.44 ; 95 \%$ CI -0.56 to $-0.31 ; p<0.00001$; $\left.I^{2}=38 \%\right)$ (Fig. 1).

\section{Rash Regression Time}

There were 5 studies involving 674 patients referring to rash regression time $[14,15,18-20]$. The random-effects model was used for the data analysis, which showed that the rash regression time in the IVIG group was sig- 


\begin{tabular}{|c|c|c|c|c|c|c|c|c|c|c|c|c|}
\hline \multirow[t]{2}{*}{ Study or subgroup } & \multicolumn{3}{|c|}{ High-dose group } & \multicolumn{3}{|c|}{ Low-dose group } & \multirow{2}{*}{$\begin{array}{l}\text { Weight } \\
\%\end{array}$} & \multirow{2}{*}{$\begin{array}{l}\text { Mean difference } \\
\text { IV, fixed, } 95 \% \mathrm{Cl}\end{array}$} & \multirow{2}{*}{\multicolumn{4}{|c|}{$\begin{array}{l}\text { Mean difference } \\
\text { IV, fixed, } 95 \% \mathrm{Cl}\end{array}$}} \\
\hline & mean & SD & total & mean & SD & total & & & & & & \\
\hline \multicolumn{13}{|c|}{ Rash regression time; IVIG $1 \mathrm{~g} / \mathrm{kg} /$ day versus IVIG $0.4-0.5 \mathrm{~g} / \mathrm{kg} /$ day } \\
\hline Fang and Pang [20], 2015 & 4.05 & 0.6 & 66 & 4.35 & 0.65 & 66 & 52.7 & $-0.30(-0.51,-0.09)$ & & & & \\
\hline Lin [18], 2015 & 6.1 & 1.6 & 20 & 5.9 & 1.4 & 20 & 2.8 & $0.20(-0.73,1.13)$ & & & & \\
\hline Lu et al. [14], 2010 & 6.23 & 1.32 & 21 & 5.95 & 1.24 & 20 & 3.9 & $0.28(-0.50,1.06)$ & & & & \\
\hline Sun [19], 2015 & 5.45 & 1.51 & 50 & 5.55 & 1.66 & 50 & 6.2 & $-0.10(-0.72,0.52)$ & & & & \\
\hline Zhang [15] , 2011 & 6.24 & 1.33 & 66 & 5.94 & 1.23 & 50 & 10.9 & $0.30(-0.17,0.77)$ & & & & \\
\hline Subtotal $(95 \% \mathrm{Cl})$ & & & 223 & & & 206 & 76.5 & $-0.15(-0.33,0.03)$ & & & & \\
\hline \multicolumn{13}{|c|}{ Heterogeneity: $\chi^{2}=7.17, \mathrm{df}=4(p=0.13) ; R^{2}=44 \%$} \\
\hline \multicolumn{13}{|c|}{ Test for overall effect: $z=1.66(p=0.10)$} \\
\hline \multicolumn{13}{|c|}{ Rash regression time: IVIG $1 \mathrm{~g} / \mathrm{kg} /$ day versus IVIG $0.2 \mathrm{~g} / \mathrm{kg} /$ day } \\
\hline Lin [18], 2015 & 6.1 & 1.6 & 20 & 6.3 & 1.5 & 20 & 2.6 & $-0.20(-1.16,0.76)$ & & & & \\
\hline Lu et al. [14], 2010 & 6.23 & 1.32 & 21 & 6.41 & 1.29 & 17 & 3.5 & $-0.18(-1.01,0.65)$ & & & & \\
\hline Sun [19], 2015 & 5.45 & 1.51 & 50 & 6.51 & 1.64 & 50 & 6.3 & $-1.06(-1.68,-0.44)$ & & & & \\
\hline Zhang [15], 2011 & 6.24 & 1.33 & 66 & 6.4 & 1.28 & 56 & 11.1 & $-0.16(-0.62,0.30)$ & & & & \\
\hline Subtotal $(95 \% \mathrm{Cl})$ & & & 157 & & & 143 & 23.5 & $-0.41(-0.73,-0.09)$ & & & & \\
\hline \multirow{2}{*}{\multicolumn{13}{|c|}{$\begin{array}{l}\text { Heterogeneity: } \chi^{2}=5.84, \mathrm{df}=3(p=0.12) ; R^{2}=49 \% \\
\text { Test for overall effect: } z=2.50(p=0.01)\end{array}$}} \\
\hline & & & & & & & & & & & & \\
\hline \multirow{2}{*}{\multicolumn{12}{|c|}{$\begin{array}{lc}\text { Total }(95 \% \mathrm{Cl}) & 380 \\
\text { Heterogeneity }: \gamma^{2}=1493 \mathrm{df}=8(n=006) \cdot R^{2}=46 \%\end{array}$}} & \\
\hline & & & & & & & & & & & & \\
\hline \multirow{2}{*}{\multicolumn{9}{|c|}{$\begin{array}{l}\text { Test for overall effect: } z=2.67(p=0.008) \\
\text { Test for subgroup differences: } \chi^{2}=1.91, \mathrm{df}=1(p=0.17) ; \ell^{2}=47.8 \%\end{array}$}} & -1 & -0.5 & 0.5 & 1 \\
\hline & & & & & & & & & & $\begin{array}{l}\text { igh-dose } \\
\text { group }\end{array}$ & $\begin{array}{l}\text { Low-dose } \\
\text { group }\end{array}$ & \\
\hline
\end{tabular}

Fig. 2. Forest plot of subgroup analysis of rash regression time among IVIG groups of different doses.

\begin{tabular}{|c|c|c|c|c|c|c|c|c|c|c|}
\hline \multirow[t]{2}{*}{ Study or subgroup } & \multicolumn{3}{|c|}{ High-dose group } & \multicolumn{3}{|c|}{ Low-dose group } & \multirow{2}{*}{$\begin{array}{l}\text { Weight } \\
\%\end{array}$} & \multirow{2}{*}{$\begin{array}{l}\text { Mean difference } \\
\text { IV, random, } 95 \% \mathrm{Cl}\end{array}$} & \multirow{2}{*}{\multicolumn{2}{|c|}{$\begin{array}{l}\text { Mean difference } \\
\mathrm{IV} \text {, random, } 95 \% \mathrm{Cl}\end{array}$}} \\
\hline & mean & SD & total & mean & SD & total & & & & \\
\hline \multicolumn{11}{|c|}{ Remission time of nervous symptoms: IVIG $1 \mathrm{~g} / \mathrm{kg} /$ day versus IVIG $0.4-0.5 \mathrm{~g} / \mathrm{kg} / \mathrm{day}$} \\
\hline Fang and Pang [20], 2015 & 3.75 & 1.82 & 66 & 3.85 & 1.69 & 66 & 15.1 & $-0.10(-0.70,0.50)$ & & \\
\hline Sun [19], 2015 & 9.24 & 2.56 & 50 & 9.74 & 2.87 & 50 & 9.3 & $-0.50(-1.57,0.57)$ & $=$ & \\
\hline Sun et al. [21], 2012 & 4 & 1.8 & 23 & 4.2 & 1.9 & 24 & 9.4 & $-0.20(-1.26,0.86)$ & $\rightarrow$ & \\
\hline Yu and Chu [16], 2013 & 3.28 & 0.46 & 25 & 4.12 & 0.6 & 25 & 19.2 & $-0.84(-1.14,-0.54)$ & 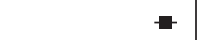 & \\
\hline Subtotal $(95 \% \mathrm{Cl})$ & & & 164 & & & 165 & 53.1 & $-0.50(-0.95,0.05)$ & & \\
\hline \multicolumn{11}{|c|}{$\begin{array}{l}\text { Heterogeneity: } \tau^{2}=0.09, \chi^{2}=5.58, \mathrm{df}=3(p=0.13) ; R^{2}=46 \% \\
\text { Test for overall effect: } z=2.19(p=0.03)\end{array}$} \\
\hline \multicolumn{11}{|c|}{ Remission time of nervous symptoms: IVIG $1 \mathrm{~g} / \mathrm{kg} /$ day versus IVIG $0.2 \mathrm{~g} / \mathrm{kg} /$ day } \\
\hline Hao and Han [17], 2010 & 1.98 & 1.52 & 293 & 2.03 & 1.32 & 340 & 20.0 & $-0.05(-0.27,0.17)$ & 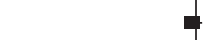 & \\
\hline Sun [19], 2015 & 9.24 & 2.56 & 50 & 11.32 & 3.65 & 50 & 7.8 & $-2.08(-3.32,-0.84)$ & $\longrightarrow$ & \\
\hline Yu and Chu [16], 2013 & 3.28 & 0.46 & 25 & 4.2 & 0.65 & 25 & 19.1 & $-0.92(-1.23,-0.61)$ & - & \\
\hline Subtotal $(95 \% \mathrm{Cl})$ & & & 368 & & & 415 & 46.9 & $-0.83(-1.67,0.01)$ & & \\
\hline \multicolumn{11}{|c|}{$\begin{array}{l}\text { Heterogeneity: } \tau^{2}=0.45, \chi^{2}=27.14, \mathrm{df}=2(p<0.00001) ; P^{2}=93 \% \\
\text { Test for overall effect: } z=1.93(p=0.05)\end{array}$} \\
\hline Total $(95 \% \mathrm{Cl})$ & & & 532 & & & 580 & 100.0 & $-0.59(-1.03,-0.15)$ & $>$ & \\
\hline \multicolumn{9}{|c|}{ Heterogeneity: $\tau^{2}=0.23, \chi^{2}=35.76, d f=8(p<0.00001) ; l^{2}=83 \%$} & $\begin{array}{ll}1 & 1 \\
-4 & -2\end{array}$ & 2 \\
\hline \multicolumn{9}{|c|}{$\begin{array}{l}\text { Test for overall effect: } z=2.66(p=0.008) \\
\text { Test for subgroup differences: } \chi^{2}=0.45, \mathrm{df}=1(p=0.50) ; l^{2}=0 \%\end{array}$} & $\begin{array}{l}\text { High-dose } \\
\text { group }\end{array}$ & $\begin{array}{l}\text { Low-dose } \\
\text { group }\end{array}$ \\
\hline
\end{tabular}

Fig. 3. Forest plot of subgroup analysis of remission time of neurological symptoms among IVIG groups of different doses. 


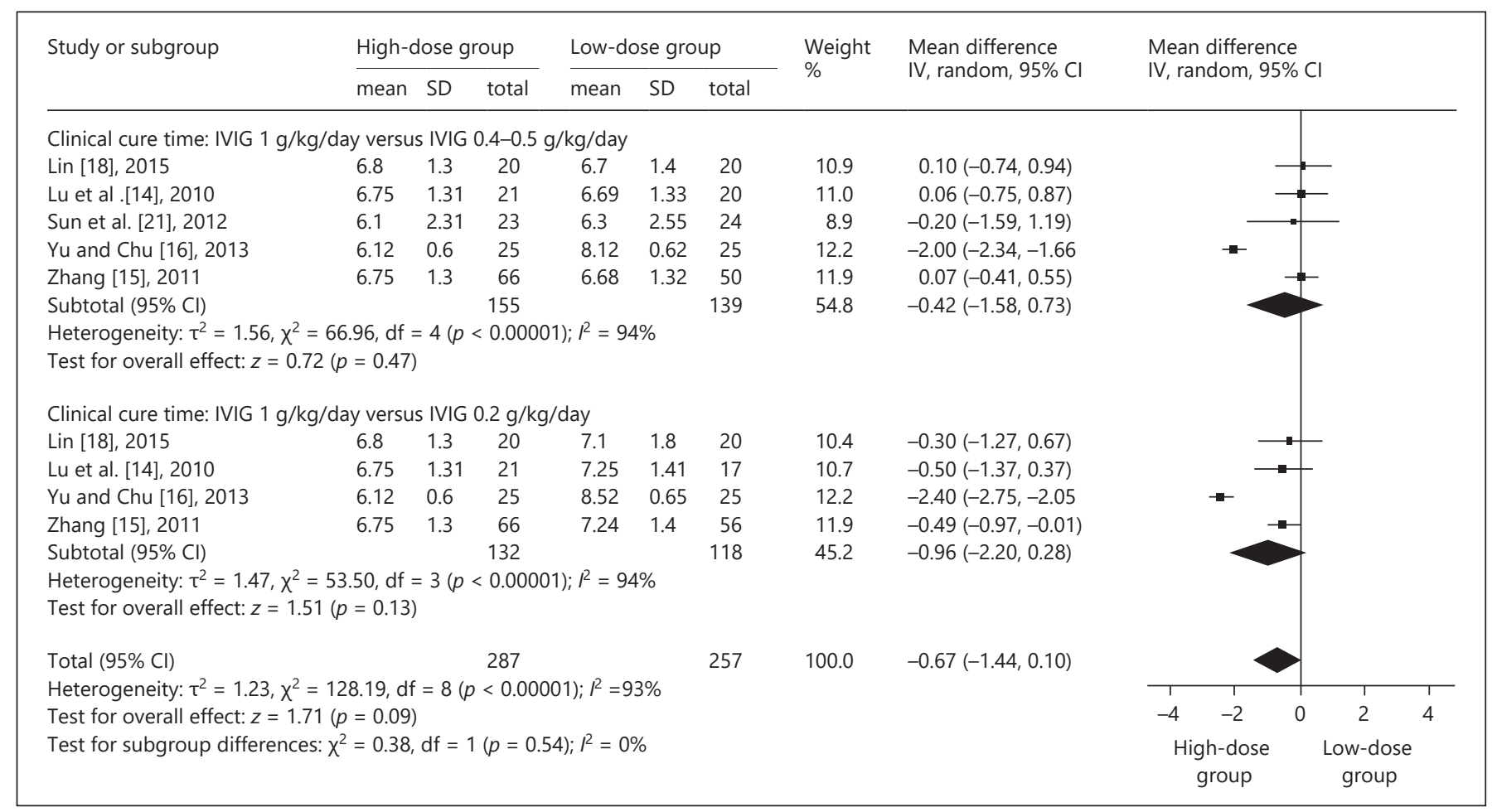

Fig. 4. Forest plot of subgroup analysis of clinical cure time among IVIG groups of different doses.

nificantly shorter than that in the control group, and the difference was significant (mean difference $=-0.53 ; 95 \%$ CI -0.96 to $\left.-0.1 ; p<0.05 ; I^{2}=84 \%\right)$. The fixed-effects model was used for subgroup analysis; it showed that the rash regression time in the high-dose group was significantly shorter than that in the low-dose group (mean difference $=-0.21 ; 95 \%$ CI -0.37 to $-0.06 ; p<0.05 ; I^{2}=46 \%$ ) (Fig. 2).

\section{Remission Time of Neurological Symptoms}

There were 5 studies involving 1,126 patients referring to remission time of neurological symptoms $[16,17,19-$ 21]. According to the existing literature [12], the remission time of neurological symptoms in the IVIG groups was shorter than that in the control group. The randomeffects model was used for subgroup analysis, which showed that the remission time of neurological symptoms in the high-dose group was significantly shorter than that in the low-dose group, and the difference was significant (mean difference $=-0.59 ; 95 \% \mathrm{CI}-1.03$ to $-0.15 ; p<0.05 ; I^{2}=83 \%$ ) (Fig. 3).

\section{Clinical Cure Time}

There were 5 studies involving 467 patients referring to clinical cure time $[14-16,18,21]$. The fixed-effects model showed that the clinical cure time in the IVIG groups was significantly shorter than that in the control group (mean difference $=-1.78 ; 95 \%$ CI -2.15 to -1.42 ; $\left.p<0.00001 ; I^{2}=0 \%\right)$. Subgroup analysis was performed among IVIG groups of different doses, and it showed that there was no significant difference between the high-dose group and the low-dose group (mean difference $=-0.67$; $95 \% \mathrm{CI}-1.44$ to $0.10 ; p=0.09 ; I^{2}=94 \%$ ) (Fig. 4 ).

\section{Incidence of Adverse Effects}

There was only 1 study referring to adverse effect incidence [19]. According to this study, the incidence of adverse effects in the high-dose group was higher than that in the low-dose group, and the difference was significant.

\section{Sensitivity Analysis}

The sensitivity analysis was conducted after the exclusion of a few articles of poor quality; the result was stable, which meant that the stability of this meta-analysis was good. 


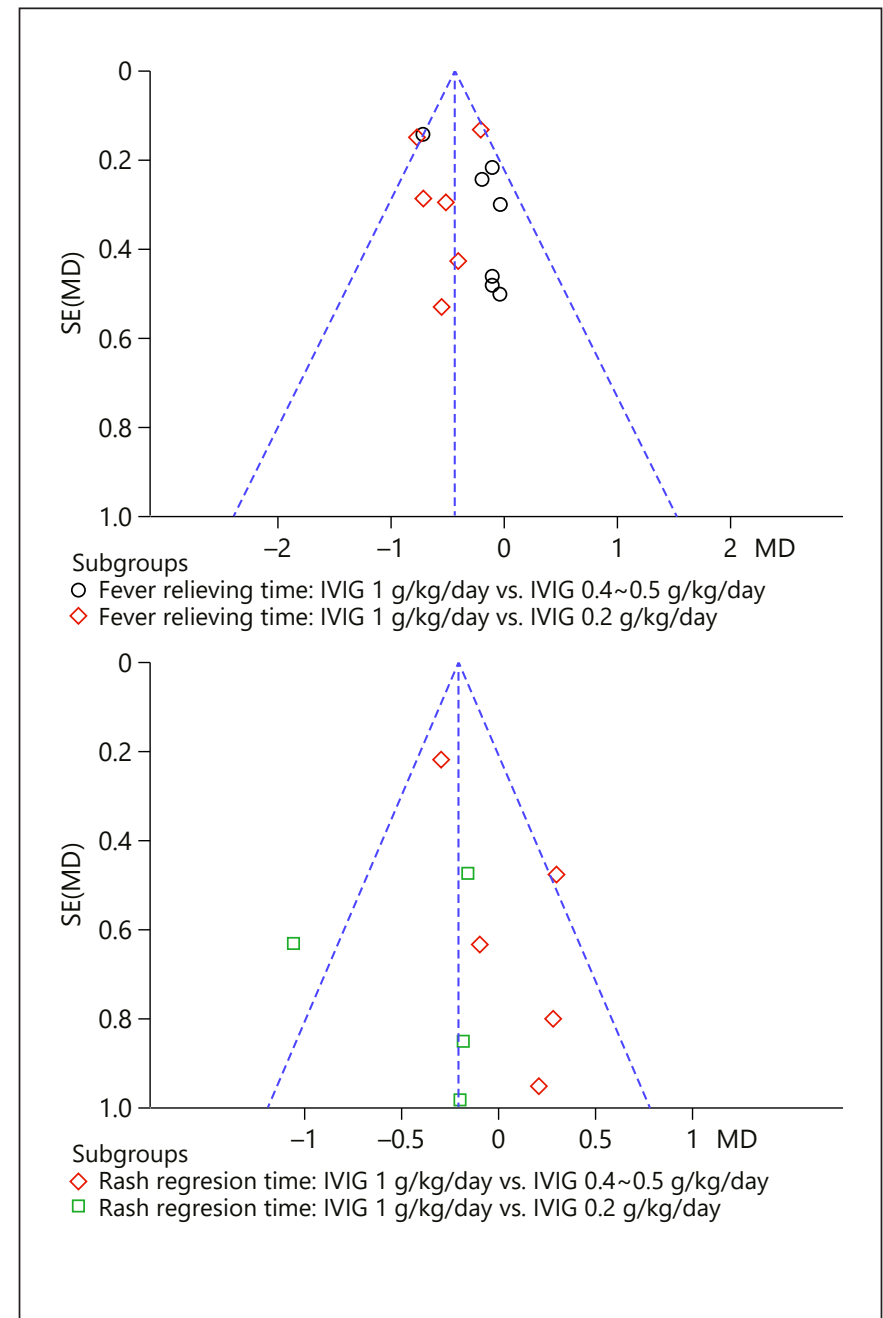

Fig. 5. Funnel plots of subgroup analysis of fever clearance time and rash regression time among IVIG groups of different doses. SE(MD), standard error of mean difference.

Publication Bias

We selected fever clearance time and rash regression time (Fig. 5) as indicators for the analysis of publication bias, and the result showed that there were different degrees of publication bias in both fever clearance time and rash regression time.

\section{Discussion}

HFMD is a common acute infectious disease in children caused by Enterovirus A. Numerous studies have shown that IVIG has certain curative or mitigating effects on viral and bacterial infections [5-9]. The Guide
(2010 Edition) [12] and Expert Consensus (2011 Edition) [13] recommend the use of IVIG in severe HFMD, but do not provide explicit descriptions of the dosage and course of the treatment. There is a big controversy over the dosage and course of treatment in the clinical application.

In this study, we focused on the effect of different doses of IVIG on severe HFMD, in order to provide the scientific basis for the rational use of IVIG in the treatment of severe HFMD and provide the basis for the reduction of financial burden to patients.

The results of the meta-analysis show that there are significant differences between IVIG groups and the control group. The IVIG groups had shorter fever clearance time $(p<0.00001)$, shorter rash regression time $(p<0.05)$, and shorter clinical cure time $(p<0.00001)$ compared to the conventional therapy group. Subgroup analysis showed that the high-dose group had shorter fever clearance time $(p<0.00001)$, shorter rash regression time $(p<0.05)$, shorter remission time of neurological symptoms $(p<0.05)$, and longer clinical cure time compared to the low-dose group $(p>0.05)$. As compared to conventional therapy alone, different doses of IVIG combined with conventional therapy can improve the effect on severe HFMD. In the subgroup analysis, the curative effect in high-dose group $(1.0 \mathrm{~g} / \mathrm{kg} /$ day) was better.

\section{Conclusions}

Treatment regimens should be selected according to the economic conditions and wishes of patients to achieve optimal outcome with ideal curative effect, short course of treatment and low cost as much as possible. High-dose IVIG can be used for severe patients based on good potency ratio and safe treatment result; low-dose IVIG can be used for patients who are stable to reduce costs.

There are several limitations in this study. (1) There were only 8 studies included in the analysis, which may lead to publication bias and thus reduce the validity of the conclusion. (2) In 8 studies included in the study, only 1 study used the random number table method, while other studies did not mention the grouping method, and there was no description of the specific situation of allocation concealment and blinding in all studies; therefore, we may have selection bias, measurement bias, and information bias. More high-quality studies are needed to verify our conclusions. 


\section{Statement of Ethics}

All procedures performed in studies involving human participants were in accordance with ethical standards of the institution and/or national research committee and with the 1964 Helsinki Declaration and its later amendments or comparable ethical standards. Since this was a meta-analysis study, no formal consent was required.

\section{Disclosure Statement}

The authors have no conflicts of interest to disclose.

\section{References}

1 Huang FL, Jan SL, Chen PY, Chi CS, Wang TM, Fu YC, et al. Left ventricular dysfunction in children with fulminant enterovirus 71 infection: an evaluation of the clinical course. Clin Infect Dis. 2002 Apr;34(7):1020-4.

2 Lin TY, Chang LY, Hsia SH, Huang YC, Chiu $\mathrm{CH}$, Hsueh C, et al. The 1998 enterovirus 71 outbreak in Taiwan: pathogenesis and management. Clin Infect Dis. 2002 May;34 Suppl 2:S52-7.

3 Chen XN. SIRS/sepsis theories and their use for guiding diagnosis and treatment of severe viral infection-A discussion based on hand, foot and mouth disease. Clin Pediatr Emerg Med. 2010;17:87-8.

4 Wang JN, Yao CT, Yeh CN, Huang CC, Wang SM, Liu CC, et al. Critical management in patients with severe enterovirus 71 infection. Pediatr Int. 2006 Jun;48(3):250-6.

5 Kaneko Y, Nimmerjahn F, Ravetch JV. Antiinflammatory activity of immunoglobulin G resulting from Fc sialylation. Science. 2006 Aug;313(5787):670-3.

6 Hemming VG. Use of intravenous immunoglobulins for prophylaxis or treatment of infectious diseases. Clin Diagn Lab Immunol. 2001 Sep;8(5):859-63.

7 Mouthon L, Lortholary O. Intravenous immunoglobulins in infectious diseases: where do we stand? Clin Microbiol Infect. 2003 May; 9(5):333-8.
8 Wang SM, Lei HY, Huang MC, Su LY, Lin $\mathrm{HC}, \mathrm{Yu}$ CK, et al. Modulation of cytokine production by intravenous immunoglobulin in patients with enterovirus 71-associated brainstem encephalitis. J Clin Virol. 2006 Sep; 37(1):47-52.

9 Wang SM, Ho TS, Shen CF, Liu CC. Enterovirus 71 , one virus and many stories. Pediatr Neonatol. 2008 Aug;49(4):113-5.

10 World Health Organization. A guide to clinical management and public health response for hand, foot and mouth disease (HFMD). Geneva, Switzerland: WHO Press; 2011.

11 Chea S, Cheng YB, Chokephaibulkit K, Chotpitayasunondh T, Rogier van Doorn H, Hafy Z, et al. Workshop on use of intravenous immunoglobulin in hand, foot and mouth disease in Southeast Asia. Emerg Infect Dis. 2015 Jan;21(1):e140992.

12 Ministry of Health of the People's Republic of China. Diagnosis and treatment guideline on hand-foot-mouth disease. Int J Respir. 2010; 30:1473-5.

13 Clinical Experts Group of the Ministry of Health for Hand, Foot and Mouth Disease. [Experts consensus on rescue and treatment of severe cases with enterovirus 71 (EV71) infection]. Zhonghua Er Ke Za Zhi. 2011 Sep; 49(9):675-8.

14 Lu GL, Ren XY, Ma BK. The Curative effect observation of different doses of gamma globulin in the treatment of severe hand foot mouth disease. Clin Pediatr Emerg Med. 2010;17:274-5.
15 Zhang Y. The curative effect observation of different doses of gamma globulin in the treatment of severe hand foot mouth disease. Chin Comm Doc. 2011;13:81.

$16 \mathrm{Yu} \mathrm{YF}$, Chu LZ. Effect of different doses of intravenous immunoglobulin in the treatment of severe hand foot mouth disease combined with encephalitis. Chin J Obstet Gynecol. 2013;9:184-6.

$17 \mathrm{Hao} \mathrm{JH}$, Han ZH. The effect of different doses of gamma globulin in the treatment of severe hand foot mouth disease. Zhonghua Shiyong Erke Linchuang Zazhi. 2010;25:1684-5.

18 Lin YQ. The clinical efficacy of different doses of IVIG in treatment of severe hand foot mouth disease. Chin Med Pharmacol. 2015;5: 42-4.

19 Sun SY. Application of intravenous immunoglobulin in the treatment of severe hand, foot and mouth disease in children. Chin Pract Med. 2015;10:146-7.

20 Fang XY, Pang XJ. Clinical observation of 2 HFMD period of low dose intravenous immunoglobulin therapy. Chin Med Eng. 2015; 23:112-4.

21 Sun WQ, et al. The curative effect observation of gamma globulin treats infants with severe hand, foot and mouth disease. J Pract Med. 2012;28:414-6.

$22 \mathrm{Xu} \mathrm{P,} \mathrm{Shi} \mathrm{BH,} \mathrm{Sun} \mathrm{YH.} \mathrm{Efficacy} \mathrm{and} \mathrm{safety}$ of intravenous immunoglobulin for severe hand, foot and mouth disease in China: a meta-analysis. Chin J Evid Based Med. 2016; 16:87-95 